\title{
Trampoline-related injuries in Hong Kong
}

MY Cheung, MB, BS, CL Lai, MB, BS, Wilson HY Lam, MB, BS, James SK Lau *, BSc, MB, BS, Aaron KH Lee, MB, ChB,

Gabrielle G Yuen, MB, BS, YK Chan, FRCS, FHKAM (Orthopaedic Surgery), WL Tsang, FRCS, FHKAM (Orthopaedic Surgery)

Department of Orthopaedics and Traumatology, Pamela Youde Nethersole Eastern Hospital, Chai Wan, Hong Kong

* Corresponding author: jameslau@gmail.com

Hong Kong Med J 2016;22:81-4

DOI: $10.12809 / \mathrm{hkmj} 144411$

\section{Case reports}

The following three cases highlight the potential serious consequences of trampolining.

\section{Case 1: Lisfranc fracture}

A 27-year-old woman with good past health was admitted with left foot pain and swelling in July 2014. She fell with axial loading on an inverted and plantar-flexed left foot while trampolining. Physical examination showed bruising on the dorsum of her left foot with tenderness over the base of the first and second metatarsals. Range of movement was limited by pain. Subsequent X-ray showed widening of the Lisfranc joint with base avulsion (Fig a). Lisfranc fracture was diagnosed. Open reduction with screw and $\mathrm{K}$-wire fixation were performed and a resting ankle-foot orthosis was given. On follow-up 2 weeks after surgery, sensation and circulation in the toes were good. Range of movement was still limited by pain, however. She was encouraged to move her ankle and toes, and to mobilise with heel-walking at 6 weeks postoperatively.

\section{Case 2: vertebral fracture}

A 25-year-old swimming instructor with good past

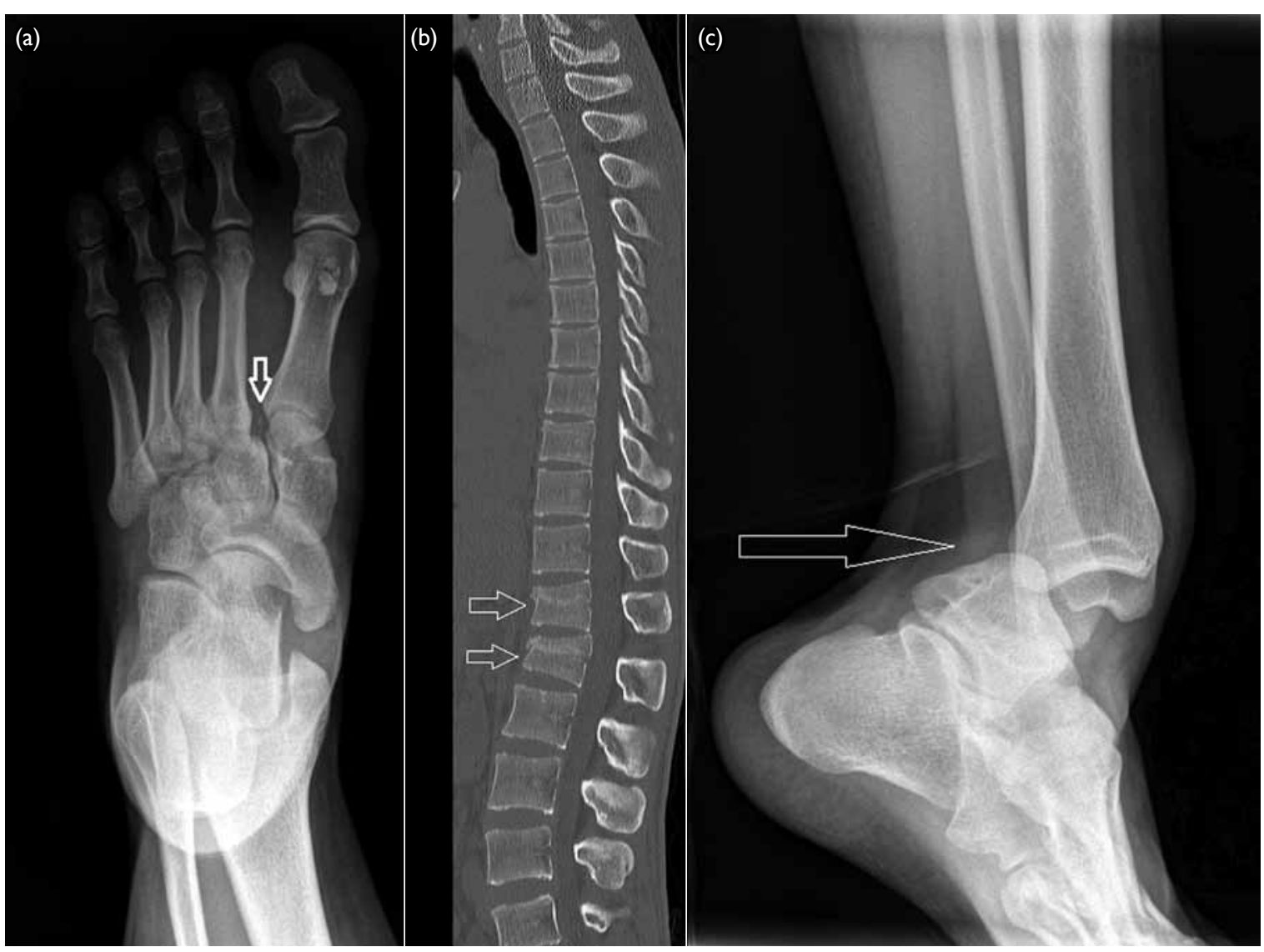

FIG. Images of the case illustrations

(a) X-ray of the left foot (dorsoplantar view) of patient I showing widening of Lisfranc joint (arrow). (b) Computed tomography of the spine (reconstructed sagittal view) of patient 2 demonstrating two-column fractures of TI 2 and LI (arrows). (c) X-ray of the left ankle (lateral view) of patient 3 illustrating posterior talus dislocation (arrow) 
health was admitted for thoracolumbar back pain after jumping and falling from 1 metre while trampolining in August 2014. He landed on his upper back with his body flexed on a trampoline. On examination, there was local tenderness at the thoracolumbar junction. His power and sensation across L 2 to S1 were normal, reflexes were present, and anal sensation and tone were intact. Lumbosacral spine X-ray showed collapsed T12 and L1 with local kyphosis of $25^{\circ}$. Computed tomographic scan was performed subsequently, detailing a two-column fracture of T12 and L1 with anterior wedging of $20 \%$ (Fig b). He was put on a rigid thoracolumbar orthosis for 8 weeks and prescribed analgesics. Close monitoring for further collapse was warranted. During follow-up, he had no complaints of pain or neurological symptoms. Follow-up X-ray of the lumbosacral spine was static.

\section{Case 3: ankle dislocation}

A 22-year-old woman with good past health was admitted with left ankle pain and deformity after landing on a trampoline with plantar flexion and ankle inversion in August 2014. Physical examination revealed a deformed left ankle joint in medial rotation and plantar flexion. There was bruising over the left foot dorsum and marked tenderness over the whole ankle joint line. She could move her toes only slightly. Distal circulation was intact, but sensation was reduced over her left foot and toes. X-ray of the left ankle showed posterior talus dislocation without definite fracture (Fig c). Closed reduction was performed under sedation and a short leg slab was applied. Post-reduction X-ray showed a congruent ankle joint. Computed tomography showed no fracture. Magnetic resonance imaging of the left ankle showed small cortical fractures at the medial body of talus and posterior aspect of distal talus, complete tear of the calcaneofibular ligament and anterior talofibular ligament, and a partial thickness tear of the deep deltoid ligament. Immobilisation with a short leg cast is planned after oedema has subsided.

\section{Discussion}

In Hong Kong, trampolining was once a part of school physical education classes since it improves motor control and increases physical activity. ${ }^{1}$ However, following a trampoline incident in 1991 that resulted in quadriplegia, ${ }^{2}$ its popularity dwindled. Since the opening of the first trampoline park in Hong Kong in late July 2014, ${ }^{3}$ an increase in the number of trampoline-related injuries requiring admission to our department has been noted. Eight trampoline-related admissions were observed in less than 2 months. It has been estimated that the incidence of injuries that required admission to our unit was 1.9 per $10000 .^{4}$ The reasons of admission included Lisfranc fracture, vertebral fracture, ankle dislocation, anterior cruciate ligament tear of the knee, and neck and back sprains (Table). All patients were previously healthy but had no trampolining experience when they attended the indoor trampoline park for recreation and injured themselves while landing on a trampoline mat. Physicians and the general public need to be aware that trampolining can result in significant injuries,

TABLE. Summary of cases admitted to Department of Orthopaedics and Traumatology, Pamela Youde Nethersole Eastern Hospital from 25 July to 6 September 2014

\begin{tabular}{|c|c|c|c|c|}
\hline $\begin{array}{l}\text { Age (years)/ } \\
\text { gender }\end{array}$ & Cause of injury & Mechanism of injury & Diagnosis & Treatment \\
\hline $27 / F$ & $\begin{array}{l}\text { Awkward landing on trampoline: } \\
\text { left foot }\end{array}$ & $\begin{array}{l}\text { Axial loading on plantar-flexed } \\
\text { and inverted left foot }\end{array}$ & Lisfranc fracture & $\begin{array}{l}\text { Open reduction and internal } \\
\text { fixation }\end{array}$ \\
\hline $26 / F$ & $\begin{array}{l}\text { Awkward landing: left foot } \\
\text { caught between two trampolines } \\
\text { on landing, body fell backward }\end{array}$ & $\begin{array}{l}\text { Sudden rotational force on } \\
\text { plantar-flexed forefoot }\end{array}$ & Partial tear of Lisfranc ligament & $\begin{array}{l}\text { Closed reduction and screw } \\
\text { fixation to left second tarsal } \\
\text { and metatarsal bones }\end{array}$ \\
\hline $22 / F$ & $\begin{array}{l}\text { Awkward landing on trampoline: } \\
\text { left foot }\end{array}$ & $\begin{array}{l}\text { Axial loading on plantar-flexed } \\
\text { and inverted foot }\end{array}$ & $\begin{array}{l}\text { Posterior ankle dislocation, } \\
\text { complete tear of calcaneofibular } \\
\text { and anterior talofibular } \\
\text { ligaments }\end{array}$ & $\begin{array}{l}\text { Closed reduction } \\
\text { Short leg cast }\end{array}$ \\
\hline 22/M & $\begin{array}{l}\text { Awkward landing on trampoline: } \\
\text { rotated left leg }\end{array}$ & $\begin{array}{l}\text { Femur and tibia rotated in } \\
\text { opposite directions on landing }\end{array}$ & $\begin{array}{l}\text { Left knee anterior cruciate } \\
\text { ligament tear }\end{array}$ & $\begin{array}{l}\text { Elective anterior cruciate } \\
\text { ligament reconstruction }\end{array}$ \\
\hline $25 / M$ & $\begin{array}{l}\text { Awkward landing on trampoline: } \\
\text { back }\end{array}$ & Hyperflexion of back & $\begin{array}{l}\text { T12 and L1 wedge collapse } \\
\text { fracture }\end{array}$ & $\begin{array}{l}\text { Thoracolumbar orthosis } \\
\text { until fracture stabilises }\end{array}$ \\
\hline $30 / F$ & $\begin{array}{l}\text { Awkward landing on trampoline: } \\
\text { back }\end{array}$ & Hyperflexion of back & L2 wedge collapse fracture & $\begin{array}{l}\text { Thoracolumbar orthosis } \\
\text { until fracture stabilises }\end{array}$ \\
\hline 22/M & Performing a somersault & $\begin{array}{l}\text { Overstretch of neck and back } \\
\text { muscles }\end{array}$ & Neck and back sprain & Conservative \\
\hline $48 / \mathrm{M}$ & $\begin{array}{l}\text { Awkward landing on trampoline: } \\
\text { forehead and chin }\end{array}$ & Overstretch of neck muscle & Neck sprain & Conservative \\
\hline
\end{tabular}


leading to acute hospital admission or even early surgical attention.

\section{Literature review}

In a New Zealand study, most trampoline injuries occurred on home trampolines. ${ }^{5}$ With its limited space, home trampolining is not popular in Hong Kong, thus there is a lack of local studies. Nonetheless since the recent opening of a trampoline park in our cluster, the awareness of trampoline-related injuries has risen rapidly. In less than 2 months, eight patients were admitted for trampoline-related injuries. Their age ranged from 22 to 48 years, with seven aged between 22 and 30 years. In overseas studies, the highest incidence of injury occurred in patients under 20 years of age., ${ }^{5,6}$ This is related to accessibility to home trampolines.

Nysted and Drogset ${ }^{1}$ evaluated a total of 551 injuries, among which 292 cases were secondary to awkward landing on the trampoline ${ }^{1}$ in comparison with seven out of eight cases observed locally. The second and third most common mechanism of injury was falling off the trampoline and collision with another person, respectively. ${ }^{1}$ Falling off the trampoline is not possible in our setting since there are multiple interconnected trampolines that are levelled with a padded ground. The fourth commonly reported injury was caused by performing a somersault $(11 \%)^{1}$ on the trampoline which was the cause of injury in our eighth patient. In another study by Alexander et $\mathrm{al}^{7}$ a similar trend is seen. A majority of injuries (42\%) were due to landing badly on the trampoline. Injuries from the frame/ springs, presence of multiple jumpers, and getting on/off constituted $19 \%, 10 \%$ and $2 \%$ of all trampoline injuries, respectively. In short, serious injuries can happen even when landing on a soft surface such as a trampoline mat where participants may be less cautious.

In our report, there was a lack of injuries involving the upper extremities, contrary to the findings of overseas studies. This could be skewed by the small sample size as well as the nature of trampolining; untrained adults tend to be more conservative and land axially on their feet. Hence the majority of our cases involved the lower extremities (50\%), and is congruent with the findings of Hume et $\mathrm{al}^{5}$ and Nysted and Drogset ${ }^{1}$ (46\% and $45 \%$, respectively). Another important point to note is that injuries involving the spine are not uncommon (25\%).

Regarding the types of injury, fractures constituted a significant proportion of injuries in the studies of Nysted and Drogset ${ }^{1}$ and Chalmers et $\mathrm{al}^{8}$ (36\% and $68 \%$, respectively), and was also the case in our study (37.5\%). A small proportion of local injuries were dislocation, which is observed in the same studies. ${ }^{1,8}$

\section{Safety measures}

In addition to regular maintenance and a readily available first-aid kit, a number of measures can be taken that may lower the injury rates. Most importantly, participants should be verbally briefed by the facility provider about the risks and dangers of trampoline use. ${ }^{9}$ For example, only one participant should be on a trampoline mat at any given time. ${ }^{9}$ Black and Amadeo ${ }^{10}$ emphasised the importance of multiple jumpers as a risk factor for injuries due to the elastic recoil generated by a larger person jumping on the mat.

In order to familiarise participants with the elasticity of a trampoline, trampolines of lower elasticity should be provided for warm-up. This is a common practice in formal training, ${ }^{11}$ and may reduce the chance of awkward landing due to motor incoordination. Another suggestion is to restrict beginners from performing complex movements such as somersaults and flips. ${ }^{9}$ To achieve this, the provider may provide a separate area for advanced participants. It is important to note that padding to cover frames has not been shown to reduce injuries. ${ }^{7}$ Injury rates should be monitored ${ }^{8}$ closely by the provider so that the effectiveness of safety measures can be evaluated.

\section{Limitations and suggestions}

Injuries that did not require hospital admission were not included, such as those in patients who presented to general practitioners or who were discharged from the emergency department. Furthermore, this report can only include cases that occurred up to the time of writing. This may underestimate the problem and lead to inaccurate interpretation. It is also difficult to draw comparisons with epidemiological data from other countries where the majority of injuries arise from home trampoline use and not from trampoline parks. Lastly, although trampolining may be perceived as a dangerous physical activity, this may not be the case; the risk of injury is not high compared with other physical activities.

\section{Acknowledgement}

We thank Dr Siu-ho Wan for encouragement, guidance, and assistance throughout the preparation of the case reports.

\section{References}

1. Nysted M, Drogset JO. Trampoline injuries. Br J Sports Med 2006;40:984-7.

2. Tang SP. I want euthanasia [In Chinese]. Hong Kong: Joint Publishing (HK) Co Ltd; 2007.

3. South China Morning Post. Hong Kong's first trampoline park, Ryze, is bound to be fun. Available from: http:// yp.scmp.com/news/sports/article/90339/hong-kongsfirst-trampoline-park-ryze-bound-be-fun. Accessed 4 Sep 2014. 
4. South China Morning Post. Trampoline centre Ryze proves a summer hit with Hong Kong youth. Available from: http://www.scmp.com/news/hong-kong/article/1565201/ trampoline-centre-ryze-proves-summer-hit-hong-kongyouth. Accessed 26 Feb 2014.

5. Hume PA, Chalmers DJ, Wilson BD. Trampoline injury in New Zealand: emergency care. Br J Sports Med 1996;30:327-30.

6. Hammer A, Schwartzbach AL, Paulev PE. Trampoline training injuries-one hundred and ninety-five cases. $\mathrm{Br}$ Sports Med 1981;15:151-8.

7. Alexander K, Eager D, Scarrott C, Sushinsky G. Effectiveness of pads and enclosures as safety interventions on consumer trampolines. Inj Prev 2010;16:185-9.
8. Chalmers DJ, Hume PA, Wilson BD. Trampolines in New Zealand: a decade of injuries. Br J Sports Med 1994;28:2348.

9. Council on Sports Medicine and Fitness, American Academy of Pediatrics, Briskin S, LaBotz M. Trampoline safety in childhood and adolescence. Pediatrics 2012;130:774-9.

10. Black BG, Amadeo R. Orthopedic injuries associated with backyard trampoline use in children. Can J Surg 2003;46:199-201.

11. USA Gymnastics. Basic trampoline-the beginning steps. Available from: https://usagym.org/pages/home/ publications/technique/2000/3/basictrampoline.pdf. Accessed 8 Sep 2014. 